\title{
FASCISMO DE ESTADO E MICROFASCISMO
}

\section{DEIVISON WARLLA MIRANDA SALES ${ }^{1}$ E JORGE ALBERTO ROCHA ${ }^{2}$}

RESUMO: No século XX iríamos assistir ao advento de uma terceira alternativa política entre o capitalismo e o marxismo: o fascismo. Mussolini buscará soerguer a Itália em meio a crises profundas, ao mesmo tempo mostrando a viabilidade teórica da sua posição, denunciando as falhas dos sistemas anteriores. Mas só poderíamos ficar restritos a uma abordagem política do termo "Fascismo"? Por um lado, esse artigo tentará mostrar um pouco o nascimento histórico deste movimento político, concentrando-se nos fundamentos teóricos da sua proposta através do entendimento do próprio Mussolini. Por outro, buscamos mostrar que houve uma apropriação filosófica interessante do termo "Fascismo", alargando o seu conceito através das perspectivas de Deleuze e Guattari. Esses autores vão trabalhar com o conceito de microfascismo, não mais tomando o Estado como foco principal, mas os sujeitos e a constituição de sua subjetividade.

PALAVRAS-CHAVE: Fascismo de Estado, Sujeito, Microfascismo, Deleuze, Guattari.

ABSTRACT: In the twentieth century we would see the advent of a third political alternative between Capitalism and Marxism: the Fascism. Mussolini will seek to raise Italy in the midst of deep crises, at the same time showing the theoretical feasibility of his position, denouncing the failures of previous systems. But could we only be restricted to a political approach to the term "Fascism"? On the one hand, this article will try to show a little the historical birth of this political movement, concentrating on the theoretical foundations of its proposal through the understanding of Mussolini himself. On the other hand, we will try to show that there was an interesting philosophical appropriation of the term "Fascism", extending its concept through the perspectives of Deleuze and Guattari. These authors will work with the concept of Microfascism, no longer taking the state as the main focus, but the subjects and the constitution of their subjectivity.

KEYWORDS: Fascism of State, Subject, Microfascism, Deleuze, Guattari.

Do ponto de vista das correntes políticas a partir do advento do marxismo, o fascismo clássico italiano aparece como uma terceira via crítica e opositora entre o liberalismo, sob a roupagem do sistema capitalista, e o socialismo. Popularmente retomado, ser fascista ganhou conotações pejorativas e negativas: significa ser autoritário ou ditador, agressivo, intransigente,

\footnotetext{
${ }^{1}$ Psicólogo (UFPI) na área de Saúde Mental e Cuidado para Pessoas em Situação de Rua. Pós-graduado em Filosofia pela Universidade Estadual de Feira de Santana (UEFS). E-mail: deivisonpsi@icloud.com.

2 Professor Adjunto de Filosofia da Universidade Estadual de Feira de Santana (UEFS). Doutor em Ensino, Filosofia e História das Ciências pela Universidade Federal da Bahia (UFBA). E-mail: jorgeacr@terra.com.br.
} 
reacionário. O que isso tem de verdade? Muita coisa; ao mesmo tempo, algo de vazio: aceitando fórmulas rápidas assim ora estaríamos incorrendo em imprecisões (teria sido "fascista" o regime de Esparta, de Nero, a Santa Inquisição?...), ora significaria passar ao largo de uma compreensão fundamentada disso que foi, nas palavra de Leandro Konder, "uma nova concepção política da direita” (KONDER, 1977, p. 5).

Quanto ao aspecto histórico do movimento, concederemos aqui brevíssimas palavras sobre os motivos do seu nascimento, uma vez que nosso objetivo será concentrarmos no manancial de ideias ou concepções que sustentaram o movimento fascista de Mussolini. Nesse sentido, faremos coro com aquilo que dizia Foucault (para quem verdade e poder não andam separados; ou, em outras palavras, para quem não há incompatibilidade entre razão e violência): o perigo de um sistema político está, justamente, em sua base racional, nos princípios e preceitos explicativos que este oferece ao público: "O que é mais perigoso na violência é a sua racionalidade", dirá ele na entrevista "Foucault étudie la raison d’État" (FOUCAULT, 1994, p. 38-39).

Elementos teóricos basilares sobre o fascismo serão aqui trabalhados ouvindo a voz do próprio Mussolini, a saber, no opúsculo A doutrina do Fascismo (MUSSOLINI, 1935). Escolheremos alguns pontos essenciais relacionados à discussão que este autor vai fazer com o marxismo, embora já alertando para alguns agravantes: Mussolini não era um filósofo, mas um estadista. $\mathrm{O}$ aspecto pragmático do fascismo sobressaiu mais do que seu suposto pendor teóricoracional. Nesse sentido, pelo menos assim o interpreta Konder, seu caráter "defensivo" e "agressivo" (no combate ao marxismo ou ao liberalismo) foi também "retórico", tudo isso concorrendo para, do ponto de vista teórico, “disfarçar o seu vazio" (KONDER, 1977, p.13). Mesmo sem o rigor filosófico de um Marx, porém, Mussolini manifestava certas noções e buscava certo entendimento para estas, algo importante a se considerar no plano de discussão das ideias.

O segundo momento do presente trabalho consistirá em fazermos uma torção filosófica, por assim dizer, dos termos fascismo ou fascista para aqueles empregados por Deleuze e Guattari. Esses autores, transversalizando as áreas da filosofia, da psicanálise ou mesmo da geografia, chegam a criar termos como micropolítica, microfascismo, territorialidade... Com isso, eles propõem sair do âmbito macro da referência a sistemas de governo para o espaço infinitesimal das nossas pequenas relações quotidianas. Se o fascismo, como veremos, privilegiou o Estado sobre o indivíduo, as perspectivas dos autores acima citados sinalizarão para uma crítica do "fascismo" sob o âmbito do indivíduo e de sua subjetividade. 
Assim, como falar de uma violência em termos microfascistas? Quais agora seriam nossos inimigos, para além dos grandes blocos de nações circunvizinhas, como no movimento fascista de Estado? Como pensar em algo como um desejo fascista? Há microfascismos instalados em movimentos de resistência? Bem entendido, ao invés de falarmos sobre "sujeito", no sentido cartesiano de uma categoria plena e autônoma, falaremos sobre "processos de subjetivação". E uma pergunta crucial a ser respondida terá a ver com isso: se as "máquinas capitalísticas" tomam o sujeito como seu produto mais rentável, não engendra ela aí subjetividades microfascistas?

\subsection{Fascismo de Estado: nascimento e ideologia}

O que propiciou, do ponto de vista histórico, a emergência do fascismo? Os autores em geral elencam várias situações sociais, políticas e econômicas que o fizeram nascer, para depois prosperar. Robert Paris mostra a Itália dividida entre um "Sul agrário e pobre, sujeito à pilhagem de um Norte industrial e conquistador" (PARIS, 1976, p. 16-17). Portanto, um país mais do que desigual, agravado por políticas intestinas de protecionismo, obviamente privilegiando o "lado" mais próspero, a reboque do menos desenvolvido.

Daí a pertinência do que disse Hur (2018): o fascismo surge como um movimento para contenção das inseguranças da população no que diz respeito às consequências da guerra e da exploração do capitalismo. E essa entrada algo repartida no sistema capitalista abria as portas para uma perspectiva nacionalista e para uma ampliação (marxiana) da palavra "luta": além da luta de classes, a Itália reclamava por uma "luta das nações" entre si, com propósitos voltados para a uma política expansionista necessária ao seu fortalecimento, haja vista a Itália conviver nos seus arredores com "potências imperialistas" sempre à espreita (PARIS, 1976, p. 29).

Todo esse cenário é vivido, conforme asseverou Paxton (2007), como uma certa agitação "antiburguesa", posto que era comum uma oposição à acumulação de dinheiro, numa ambiguidade política que reunia um ódio ao capitalismo (mais propriamente, ao Estado liberal e democrático) e ao socialismo. Era preciso nascer na Itália um “"sindicalismo revolucionário"”, o qual pudesse dar conta de todos aqueles problemas. A expressão Fasci Siciliani significava uma autodenominação dos camponeses que se rebelaram contra os grandes fazendeiros da Sicília.

Paxton (2007) lembra ainda que o fascismo nascia oficialmente em Milão, na Itália, no dia 23 de março de 1919, quando uma centena de pessoas composta por sindicalistas, veteranos de guerra, intelectuais, repórteres e curiosos se reuniram na "Aliança Industrial e Comercial de 
Milão" para declarar uma guerra ao socialismo, em virtude da oposição deste ao nacionalismo. $\mathrm{Na}$ ocasião, Mussolini chamou este movimento de Fasci di Combattimento, que significa “fraternidades de combate" (PAXTON, 2007, p.16).

Segundo o autor supracitado, o programa fascista fora divulgado meses depois e era um misto de patriotismo dos veteranos com um radical experimento social. Tinha em sua estrutura objetivos de expansão da Itália nos Balcãs e nos arredores do Mediterrâneo, depois de ver esses objetivos frustrados na Conferência de Paz em Paris. Propunha voto aos 18 anos, sufrágio feminino, jornada de trabalho de 8 horas, confisco de bens da igreja e da guerra.

Paxton (2007) discute no livro A Anatomia do Fascismo ingredientes distintos do fascismo, composto por conservadorismo, nacionalismo, uma certa paixão pela purificação da Nação, antissemitismo (e acrescentamos: homofobia, exaltação da guerra e da masculinidade, busca do ideal de uma raça pura). Mann (2008) basicamente repete isso. As características basilares deste movimento seriam: nacionalismo, estatismo (só o Estado é o que importa, não o indivíduo), transcendência, expurgos e paramilitarismo.

Entender tais características, que nasceram de fatos e de compreensões ou ideias, requereria mostrar como o próprio Mussolini compreendia o movimento. A cada passo dos seus escritos poderemos ver como o fascismo se distanciava de uma perspectiva marxista e, como se verá mais adiante, como igual distanciamento é verificado em uma perspectiva de recusa microfascista, na qual o indivíduo, sua subjetividade, sua singularidade, a busca de um modo de vida próprio, enfim, é realçado para além de qualquer nivelamento, normatividade ou obediência irrestrita a outrem.

\subsection{A voz (teórico-retórica) de Mussolini}

Já dissemos mais acima: tanto para Paxton quanto para Konder o fascismo não se tratava de uma filosofia complexa, mas de uma agitação de pensamento das massas a respeito de valores construídos pelas narrativas desta ideologia a respeito de elementos como superioridade, supremacia, unificação. Elementos que ocorreram sem uma construção sistemática de pensamento subjacente, como se dera, por exemplo, com o socialismo e o liberalismo. Konder (1977), por exemplo, diz: "Para elaborar suas concepções, o fascismo foi - pragmaticamente - buscar ideias no campo do inimigo. Numa direita apavorada com a revolução proletária, era natural o impulso de macaqueá-la, 'assimilando-a' desfigurada para tentar neutralizá-la” (KONDER, 1977, p. 8). 
Essa falta de programa sistemático não era um fato elencado como vergonhoso por Mussolini. Muito pelo contrário, O estadista italiano se vangloriou certa feita nos "Postulados do Programa Fascista” de que não se prendia a nenhuma forma doutrinária. Quando questionado qual seu programa, chegou a ameaçar agredir jornalistas, e Emilio Gentile, um dos seus militantes, proferiu em 1920 uma frase que sintetiza a maneira como geria sua ideologia: "O punho é a síntese de nossa teoria...”(PAXTON, 2007, p. 40).

Para além da concordância intelectual, o fascismo produzia uma aceitação incondicional de seus adeptos, a partir do chamado "populismo". Mas, como os programas não tinham uma formalidade e concretude, isso fez com que os "intelectuais" que acompanharam os princípios deste movimento se afastassem dele ou passassem para a oposição, seja também pelas concessões ocorridas ao tomar o poder ou pelo caráter anti-intelectual destes partidos. Em todo caso, havia em Mussolini, toscamente que fosse, posições filosóficas relativas ao seu programa. Que a primeira fosse agir mais e pensar menos (nos fundamentos teórico-filosóficos do movimento) já o sabemos, mas valeria a pena mostrar alguns dos seus argumentos, colhidos no opúsculo A doutrina do Fascismo. Faremos isso tomando por base aspectos relevantes para o que falaremos no ponto a seguir sobre o microfascismo, a saber: a relação indivíduo-Estado, bem como sua conexão com certa antropologia e ética.

Disse Mussolini textualmente: "O homem do fascismo é o indivíduo que é nação e pátria, lei moral que reúne conjuntamente indivíduos e gerações numa tradição ou missão que suprime o instinto da vida encerrada na efêmera roda do prazer, para instalar no dever uma vida superior livre”.. (MUSSOLINI, 1935, p. 8). Mussolini esboça certa antropologia, baseada na concepção de um homem de vida ativa ou "viril" (veremos isso melhor depois). Esboça também a ideia de que a realização dessa vida livre só pode ser dada através da "abnegação", diz ele na sequência da citação acima. Abnegação ao que? A inclinações pessoais, sem deixar diante de si, ao contrário, elementos ligados à cultura, à história do povo, à tradição, à arte, religião e educação em geral (daí o ultranacionalismo característico do movimento).

O fascismo, desse modo, é plenamente "anti-individualista", no sentido preciso de que deve haver uma "concordância" entre indivíduo e Estado, nenhum dos dois podendo ser pensados indissociavelmente. Porém, não existe aí plena relação de igualdade. Esta concordância é antes uma sobreposição hierárquica, uma vez que é o "Estado a verdadeira realidade do indivíduo" (MUSSOLINI, 1935, p. 12). O contrário disso não se aplica, pois. Se o socialismo falava de luta de classe, e evocava a contradição e o enfrentamento intestino entre segmentos da população, é porque ele, contrariamente ao fascismo, desconhecia "a unidade 
estadual que reúne as classes numa única realidade econômica e moral" (MUSSOLINI, 1935, p. 13). O mesmo se dava com o liberalismo, mutatis mutandis: aqui, o interesse do indivíduo sobrepõe o do Estado, pelo menos quando um e outro estão - e podem plenamente estar - em lados opostos de interesse. Em suma, diz Mussolini mais adiante, o Estado é o "absoluto", o indivíduo e os grupos, o "relativo" (MUSSOLINI, 1935, p. 33).

Pensados como Estado, os indivíduos nem são ao menos representados por sua maioria. Significaria isso "rebaixá-los". Só a vontade de Um, imbuído do sentido de uma multidão verdadeiramente unida, de consciência ética "da natureza e da história" poderia reagrupar não mais o caleidoscópio de interesses singulares, mas a consciência efetiva "da nação como Estado" (MUSSOLINI, 1935, p. 13-14). O chefe de Estado, interiorizando menos a necessidade das liberdades individuais do que a norma e a disciplina a que todos deveriam adotar, realiza em si e pode disseminar na sociedade a "educação" e a promoção "da vida espiritual" (MUSSOLINI, 1935, p. 17). Mais adiante nos escritos de Mussolini, ele falará sobre algo como uma lei da natureza que já diz o essencial a ser seguido. A natureza privilegia o indivíduo ou a espécie? De um modo geral, e isso se aplica a todos os seres, dos quais nós não fugimos à regra, não é a liberdade dos indivíduos o que interessa, isso "não parece estar de acordo com os planos da natureza, nos quais somente a espécie é tomada em consideração, e o indivíduo parece sacrificado" (MUSSOLINI, 1935, p. 27-28).

Conflito perene, incessante? Isso não era problema para Mussolini, uma vez que sua concepção antropológica e mesmo teleológica era de que a finalidade do homem não era chegar a um momento de paz definitiva e apaziguadora. Imbuído de um certo vitalismo estranho, para ele "somente a guerra pode levar todas as energias humanas à máxima tensão, imprimindo um cunho de nobreza aos povos que têm a virtude de enfrentá-las” (MUSSOLINI, 1935, p. 22). É tal "espírito antipacifista" que deve ser conduzido "também à vida particular dos homens" (MUSSOLINI, 1935, p. 22). Acrescentemos, com o estadista italiano, que não estava aí descartado um amor ao próximo. Caso contrário, não estaríamos negando o sentido de pátria ou de cidadãos desta? Mussolini adverte, não obstante, que tal concepção não seria "vaga" ou “inatingível”. Amar ao próximo não impediria as "necessárias severidades educadoras e ainda menos as diferenças e distâncias" (MUSSOLINI, 1935, p. 23)

Por que seria estranho falar assim? Ora, uma coisa é admitir que nunca existirá uma paz definitiva, que vez ou outra entraremos em embate, ou uma economia estabelecida, que assegurasse a todos o seu bem-estar, sem risco de desestabilizar-se a qualquer instante. Coisa diferente, porém, é realçar a luta não como momento eventual na vida do homem ou na história 
dos povos, mas fazer dela quase que uma busca incessante, a fim de se elevar o espírito humano à sua plenitude. Ou então, no segundo caso, imaginar que viver em uma economia saudável e repartida para todos significasse "converter homens em animais que pensam numa só coisa: em comer e engordar" (MUSSOLINI, 1935, p. 25).

É a imagem desse novo homem combatente que Mussolini tem em vista, e é a existência de um homem assim que pode nos dar o argumento para dizer, contra o marxismo, que não é (só e fundamentalmente) a luta de classes que é o motor da história, mas pessoas viris, por assim dizer, que tomam sob si a tarefa de conduzir as nações. Mussolini fala, a esse respeito, de "santidade" e de "heroísmo", e esse santo e herói independe, no tocante às forças que trazem em si mesmos, dos determinantes histórico-econômicos.

\subsection{Do fascismo de Estado ao microfascismo}

A distinção entre o fascismo e o microfascismo não é de forma alguma uma simplista dicotomia, que visa produzir a afirmação de um em detrimento do outro, a supremacia de um modelo como o mais perigoso. Pelo contrário, há ramificações e possibilidades de intercruzamento entre os dois. fascismo e o microfascismo são coextensivos, atravessam-se constantemente nas realidades apresentadas.

Deleuze e Guattari (1996) afirmam que o microfascismo implica em um regime micropolítico que se ramifica em focos multiformes e plurais em vez de buscar uma centralização, como acontecera no fascismo de Estado. Cabe salientar que o prefixo micro não significa pequeno, menor, mas segue a linha da molecularidade $^{3}$, que diz respeito à variabilidade e possibilidade de se metamorfosear nos diversos contextos.

Destarte, em meio às narrativas duras do fascismo institucionalizado, o microfascismo surgiu de um processo disruptivo que desmontou as concreções para fazer emergir linhas de fuga que se metamorfoseiam em linhas de abolição e morte (DELEUZE \& GUATTARI, 1996). Estes autores ainda afirmam que uma potência micropolítica ou molecular do fascismo o torna mais perigoso, por se tratar de um movimento de massa capaz de se expandir, e não apenas um organismo unificado. Não significa, porém, que o microfascismo aponte para uma mera

\footnotetext{
${ }^{3}$ Deleuze e Guattari (1996) citam no terceiro volume do seu livro Mil Platôs: Capitalismo e Esquizofrenia, que há dois tipos de linhas que atravessam os processos de subjetivação, a saber: as de segmentaridade dura ou molares, onde os estratos representam uma maleabilidade menor como classe social, gênero; as de segmentaridade maleável ou moleculares, que representam níveis maiores de desestratificação, proporcionando movimentos de multiplicidade, esquizos, de devir que produzem transmutações.
} 
reprodução miniaturizada da segmentaridade molar do fascismo. $\mathrm{O}$ processo de molecularização do fascismo faz com que emerjam suas especificidades em linhas flexíveis, que transformam um microfascismo num processo tão complexo quanto a força dos movimentos neonazistas que têm se institucionalizado, ainda que às escuras.

Hur (2018) ratifica este cenário ao salientar que o microfascismo é estratégico por sua ação de mobilizar na esfera dos afetos e desejos mais íntimos. Instiga emoções primitivas (ainda que na esfera cognitiva, racional, isso seja nítido para a maioria) e processos repressivos como medo, ódio, insegurança, violência a partir de códigos sociais e maquínicos instituídos. O microfascismo avança na modulação dos desejos e condutas por meio da ramificação em meio ao campo aberto, sem necessidade de líderes e nem de espaços de confinamento. Há Hitlers nos diversos discursos e práticas, e todo lugar pode se tornar $\underline{A u s c h w i t z}^{4}$.

Rolnik (2018, p.74) afirma que há na atualidade um processo de "demonização do outro". Outro que pode ser uma pessoa, uma cor de pele, um povo, uma orientação sexual, uma classe, partido político, ideologia etc. Nessa demonização, microfascismos como o machismo, o racismo, a xenofobia, a lgbtfobia se destacam. Nesta operação, ocorre uma ação direta do que a autora chama de "micropolítica reativa", a qual utiliza uma bússola moral e perfaz a volta do mesmo, um retorno das maneiras de opressão que foram - em tese - superadas no nível molar, mas que ainda operam em níveis moleculares do desejo.

Guattari (1981 apud Hur, 2018, p.141) aponta que a molecularização do fascismo indica uma malha mais fina que se mostra em constante evolução, não encontrando sua força nos estratos institucionais, mas no coração e no desejo de cada um de nós. Espalha-se por todas as partes, com seus agenciamentos ${ }^{5}$ variáveis, enredando-se no campo social a partir das relações de força.

Hur (2018) afirma que nos microfascismos se manifestam posturas de rechaço ao que é diferente, ao que não se identifica aos seus códigos, não apenas no território macropolítico, mas também no campo micropolítico, da existência. Dessa forma, há uma exaltação da própria identidade, gênero, orientação sexual, religião a partir de discursos autoritários que colocam sempre o lado de fora de seus limiares como passíveis de serem eliminados. Para que estes sejam eliminados, é necessário que sejam desumanizados, animalizados, bestializados, vistos como um corpo-vírus a ser posto numa quarentena ou extinguido. Neste sentido a aniquilação

\footnotetext{
${ }^{4}$ Rede de campos de concentração da época de Adolf Hitler, foi palco de milhares de mortes na época do nazismo. ${ }^{5}$ Agenciamento é um dos conceitos centrais de Deleuze e Guattari (1996). Diz respeito aos amplos acoplamentos de conexões materiais (de corpos) e de signos (enunciação). Ou seja, uma relação de implicação mútua entre regimes de corpos e regimes de expressão em níveis plurais, incidindo na subjetividade singular ou coletiva.
} 
do outro em sua alteridade (ou como preferimos chamar: outridade) tem como subterfúgio a manutenção das identidades-codificadas, o que chamam de autosobrevivência (da moral, dos bons costumes, da família tradicional).

É preciso, porém, ampliar também o conceito de violência nos microfascismos, posto que há atitudes microfascistas que operam violências às autoridades a partir de um ethos da docilização, da correção, homogeneização, da condução tutelar com a melhor das "in-tensões". Cura, normalidade, aceitação e as ditaduras da resiliência e felicidade soam como espécies de microfascismos que utilizam maneiras eufemizadas (porém não menos violentas) de agir.

No prefácio da edição americana do livro O Anti-Édipo: Capitalismo e Esquizofrenia, de Deleuze e Guattari, Foucault (1993) situa esse fascismo no nível das condutas, dos espíritos, do cotidiano, que produz na subjetividade o amor pelo poder, ${ }^{6}$ pela dominação e exploração nos diversos níveis, importando mais a relação de poder do que o líder unificado, o partido institucionalizado, tal qual fora no Fascismo de Estado.

O amor pelo poder no microfascismo não é apenas um desejo de reprimir, coagir, negar, violentar o outro, mas também de induzir, produzir, incitar relações de forças, de afetar e ser afetado no âmbito micropolítico. Gallo (2015) afirma que nessa forma de fascismo não há a ação apenas de um fascista, o representante-mor, mas todos nós somos vítimas e algozes nas práticas e discursos do cotidiano. Ou seja, ao contrário do fascismo de Estado, que tinha no líder o principal representante, no microfascismo os "inimigos" variam de rosto, de posição, podendo ser desde o companheiro do partido ao pastor, o revolucionário ou nós mesmos.

Isso pode ser ratificado no próprio título do prefácio de Foucault à edição americana do principal livro de Deleuze e Guattari, O Anti-Édipo (1993), qualificando-o como uma introdução à vida não-fascista, a saber, desfazendo a lógica do partido, do programa, do líder, e situando tudo ao nível da vida que precisa ser liberada, ou seja, da vida fascista em seus discursos e atos. Deleuze (2006) afirma que há no fascismo um culto à morte, um grito de viva a morte. No caso do fascismo de Estado, esse grito funcionava com estratégias de exercício de poder operacionalizadas institucionalmente por ações ligadas à polícia, por exemplo. No caso do microfascismo, esse culto à morte funciona nas vias micropolíticas, dos discursos, por exemplo, nas redes sociais, onde frases como "bandido bom é bandido morto" soam como chavões, refletindo um culto desvelado pela morte.

\footnotetext{
${ }^{6}$ A noção de poder aqui falada e referida a Deleuze e Guattari é aquela tirada da posição de Michel Foucault: o poder como relação de uns sobre outros e poder "produtivo", ou seja, que não reprime, apenas. Sobre tais noções ver de Foucault Microfísica do poder (2004). Interessante também é ver como Deleuze trata deste tema no seu livro Foucault (2005), onde falar em poder é falar de forças agindo sobre forças.
} 
A esse culto pela morte o pensador camaronês Achille Mbembe (2018) chamou de Necropolítica, o que diz respeito a uma política da morte. Face ao jargão da Biopolítica descrita por Foucault, que diz "fazer viver e deixar morrer", a Necropolítica grita o "fazer morrer", transformando determinadas vidas em corpos matáveis, descartáveis, onde o Não-Eu não passa de estatística, como é o caso do genocídio de pessoas negras, dos alarmantes números do feminicídio e mortes por LGBTfobia.

\subsection{Fascismo e desejo}

Nesse sentido, a frase de Reich (1988) foi essencial na construção da relação entre desejo e campo social, combatendo visões deturpadas acerca de as massas serem enganadas, alienadas (como procuravam advertir algumas discussões marxistas). No entanto, Deleuze e Guattari (2010) afirmam que quando Reich se questionou sobre o porquê das massas desejarem o fascismo, ainda recorreu a conceitos pertencentes a um hall intrapsíquico pela via do negativo, do sadismo, fruto de inibições sexuais.

Ora, se, por um lado, há noções de desejo que o relacionam ao negativo e à falta, capitaneando-o de acordo com a Lei (a psicanálise lacaniana acredita que existem desejos demais, sendo necessário canalizá-los a partir de anestesiamentos familialistas ou fantasmáticos (DELEUZE; PARNET, 1998; LACAN, 1999)), a noção de desejo em Deleuze e Guattari (2010) é excesso e não falta, produção e não representação. Assim, o desejo de fascismo é produzido no âmbito da subjetividade por agenciamentos do poder.

Para eles, nada falta ao desejo, não há falta de objeto que o mova. A falta nunca é anterior à produção desejante, não há produção que se organize a partir da falta. Ao contrário, a falta vem a se propagar por máquinas sociais a partir de uma produção prévia (DELEUZE; GUATTARI, 2010). O que move o desejo é seu movimento nas maquinações com as quais estabelece relações. Assim, se para Deleuze e Guattari (2010) o desejo é produtivo, e produz real, não há uma separação entre produção social e de realidade, de um lado, e produção desejante, de outro. Há apenas liames entre essas duas produções. Como se as práticas sociais se duplicassem em práticas mentais, ou como se as práticas mentais se projetassem em práticas sociais.

Nas palavras do coletivo de escrita Esquizografias (2017) a respeito do que acontece no Brasil atualmente, o que preocupa não é a figura de Jair Bolsonaro como candidato com posturas reacionárias no que diz respeito ao seu posicionamento racista, lgbtfóbico, xenofóbico, 
misógino, mas sim o desejo por Bolsonaro. Desejo que se expande, que circula nas relações, que habita milhões de corpos, os quais mesmo afirmando com todos as letras que desejam "endireitar o país", desejam o "fascismo", quer dizer, a tudo que se diferencia de um território existencial majoritário: homens, héteros, brancos, cristãos, neoliberalistas, armamentistas etc.

É preciso, todavia, tecer considerações acerca da relação entre desejo e interesse. Todo social é desejante e todo desejante é social nas relações inter-agenciamentos (maquínicos dos corpos e coletivos de enunciação). Há nestes inconscientes maquínicos cenários de coexistência de investimentos libidinais inconscientes (desejo) e investimentos pré-conscientes (interesse) sem que necessariamente exista uma concordância entre eles. Podendo existir investimentos de desejo contrários aos investimentos do interesse.

Nesse tocante, faz-se mister situar a distinção dos dois polos de investimento social trazidos no $O$ Anti-Édipo, um polo paranoico, reacionário e fascista e o polo revolucionário. Enquanto o primeiro subjuga a produção desejante e a relega aos grandes conjuntos, caminha na busca de conjuntos molares e estruturados e esmaga as singularidades, parando os fluxos descodificados em nome de reterritorializações que objetivam as identitarizações dos grupos sujeitados, o segundo segue a potência das multiplicidades moleculares dos processos de singularizações, engendrado por linhas de fuga que afirmam a produção de novos fluxos dos grupos sujeitos.

Segundo os autores, é possível que ocorra nas subjetividades (singulares ou coletivas) o processo de desejar realidades contrárias aos interesses, ideais que no nível dos investimentos pré-conscientes deveriam ser combatidos, mas que são desejados no nível inconsciente. No que diz respeito ainda à relação Desejo e Interesse, Deleuze e Guattari (2010) afirmam que o interesse pode ser enganado, desconhecido ou traído; já o desejo não, ele não pode ser enganado.

Dessa forma, quando assistimos a subjetividades microfascistas que contrariam os interesses em seus níveis pré-conscientes, é preciso pensar que ainda assim houve um desejo de fascismo. Como afirmam os autores: "Portanto, é concebível que um grupo possa ser revolucionário do ponto de vista do interesse de classe e dos seus investimentos pré-conscientes, mas não sê-lo do ponto de vista dos seus investimentos libidinais, e manter-se até mesmo fascista e policial" (DELEUZE E GUATTARI, 2010; p.462). Nesse sentido, é preciso reconhecer que o microfascismo não habita apenas os inconscientes dos grupos reacionários instituídos (neonazistas, grupos racistas, ligados à política conservadora), mas também nos movimentos de resistência, ligados a um pensamento mais progressista. 
Os discursos e atos microfascistas se protegem sob o escudo de uma pretensa "liberdade de expressão" que se configura, na verdade, como uma liberdade de opressão. O que é possível observar nos comentários de sites, blogs e redes sociais, nos banheiros de universidades públicas ou nas ruas. Esses discursos e atos são perpetuados em relações de conivência e concordância que fazem novamente o desejo de fascismo emergir, ainda que uma suposta neutralidade apareça em termos de interesse pré-consciente.

É necessário salientar que há um retorno, nos dias atuais, ao primeiro grupo supracitado, de narrativas reacionárias, utilizando ideais como família, moral e bons costumes como mote para suas práticas de intolerância, daquilo que foge aos seus limites. Fato que é preciso ser analisado de maneira crítica, posto que, como afirmam Deleuze e Guattari (2010), por vezes o microfascismo fala a linguagem da ordem, da razão, fazendo coexistir uma linguagem de investimento pré-consciente baseada no discurso do bem comum e um desejo fascista de eliminação de algum fluxo de diferença em relação a determinados territórios constituídos moralmente como parâmetro.

Retomando a ideia de que os microfascismos independem de marcadores históricos, geográficos e macropolíticos, Guattari, no livro Linhas de Fuga (2013), afirma que, diferentemente do Fascismo Histórico Molar, o Microfascismo se expandiu no nível das massas, existindo inclusive nos países ditos democráticos. O que é feito por meio de estratégias de agenciamentos de poder na maquinação do desejo, que procedem de maneira sutil na expropriação da subjetividade em níveis coletivos ou individuais, sem necessitar de um referente externo que o sustente, como uma nação rígida em suas fronteiras e seu nacionalismo, um partido articulado, um líder. É necessário, dessa forma, compreendermos os processos de subjetivação, para que seja possível compreender a fundo o microfascismo.

\subsection{Máquinas capitalísticas e produção de subjetividades microfascistas}

Indo de encontro às noções tradicionais de identidade que trazem a ideia de um eu estável, universalizado, indivisível, são visíveis os rastros de uma crise do eu, a partir do desfalecimento dos pilares instituídos acerca de um sujeito universal, unificado, intrapsíquico, individualizado, em uma atmosfera de unificação e totalização (DOMÈNECH; TIRADO; GÓMEZ, 2001).

A concepção de subjetividade aqui utilizada seguirá outra via, pautando-se, sobretudo, no conceito de "Processos de Subjetivação", criado pelo filósofo Gilles Deleuze e pelo psicanalista Félix Guattari. Nesse universo, as perspectivas identitárias, essencializadas, 
universais e unitárias de subjetividade perdem força multiplicitória e estética, marcadas pela diferença em vez da identidade, pela multiplicidade em vez da unidade, pela singularidade em vez da universalidade, heterogeneidade em vez da homogeneidade. Assim, enquanto boa parte da tradição filosófica afirmou a subjetividade numa filosofia da Identidade, Deleuze e Guattari (2010) (entre outros da sua geração, cada um ao seu modo) a colocam no hall da diferença. A seguir discutiremos conceitos fundamentais para a compreensão do conceito de processos de subjetivação na perspectiva deleuzoguattariana.

Nos processos de subjetivação, entra em cena a ideia de subjetividades produzidas incessantemente por meio da relação entre o dentro (inconsciente) e o fora (socius). Essa lógica é apreendida a partir do conceito de inconsciente maquínico de Deleuze e Guattari, que consideram o inconsciente como uma espécie de usina de produção de realidades, onde o desejo é pura produção de real. Essa perspectiva segue uma direção diferente da psicanálise por desindividualizar o inconsciente, desedipianizá-lo, mostrando um desejo coletivo, um inconsciente que extravasa os limites do eu individualizado.

Nesta produção de subjetividades, há o funcionamento de máquinas de natureza "extra pessoal, extra individual, infra-humana, infrapsíquica e infrapessoal", ratificando uma espécie de co-funcionamento de fatores de produção das subjetividades de maneira incessante e não finalizada (GUATTARI; ROLNIK, 1993, p. 31). Nesse processo de produção de subjetividades podem interatuar máquinas de ordens plurais, sem que qualquer uma dessas tenha uma relação hierárquica ou de classificação temporal, como já fora dito anteriormente. Em suma, quaisquer encontros em que o desejo circule em seus fluxos e cortes, produzindo interferências no plano da memória, da inteligência, dos afetos, do inconsciente. Isso nos faz compreender a heterogeneidade dos componentes maquínicos de engendramento de subjetividades, podendo ser desde aqueles ligados à escola, arte, esporte, aos ligados pela mídia, cinema, entre outros.

É necessário conceber as Máquinas Capitalísticas ${ }^{7}$ de produção de subjetividades como pertencentes ao que Guattari e Rolnik (1993) chamam de Capitalismo Mundial Integrado - CMI - (em contraposição à utilização do conceito Globalização, rechaçado por ele). O CMI é caracterizado pelo capitalismo pós-industrial, que descentra suas estruturas de produção de serviços e bens e se volta para a produção de subjetividades. Como dizem Guattari e Rolnik (1993), a subjetividade é o produto mais rentável das Sociedades Capitalísticas, por ser matériaprima de toda e qualquer outra produção.

\footnotetext{
${ }^{7}$ A expressão "capitalísticas" foi cunhada por Félix Guattari em Guattari e Rolnik (1993) para qualificar não apenas as sociedades do capitalismo clássico, mas também aquelas que vivem sobre o seu jugo, como os setores do Terceiro Mundo, do Capitalismo Periférico, os quais pouco ou nada se diferenciam no nível das subjetividades.
} 
Guattari (2010), no seu labiríntico livro Caosmose, afirma da maneira mais lapidar que o capitalismo se apoderou de nós por dentro, controlando e gerindo nossa subjetividade. $\mathrm{O}$ personagem "Estamira", apresentada no documentário homônimo de Marcos Prado, ${ }^{8}$ foi quem melhor ilustrou esse cenário com a denúncia do Trocadilo que utiliza seu controle remoto por meio de uma relação de forças busca controlar, seduzir, cegar, incentivar e "depois jogar no abismo".

Não nos é novidade que as Máquinas Capitalísticas utilizem em seu plano de produção de subjetividades uma lógica majoritária de partir de subjetividades logradas no hall dos esquemas hegemônicos. Assim, os vetores de subjetivação (molares e moleculares, humanos e não-humanos) partem dos parâmetros, das formas e fôrmas do homem $C I S$, branco, europeu, heterossexual, cristão. O que Rolnik (2018) dá o nome de Antropo-Falo-Ego-Logo-Cêntrico para qualificar uma produção majoritária, hegemônica, reativa de pensamento, engendrada por uma ação de colonização dos inconscientes por meio da reterritorialização dos fluxos inconscientes que fogem aos códigos instituídos pelo capitalismo.

Há de se dizer, igualmente, que o desejo de fascismo não funciona apenas direcionado ao outro, posto que as máquinas capitalísticas engendram subjetividades capazes de gritar pelo seu próprio suplício, numa atualização de Espinosa (1677 apud DELEUZE; GUATTARI, 2010, p. 46), quando questionava algures: "Por que os homens combatem por sua servidão como se se tratasse da sua salvação?", ou à luz de Etienne de La Boétie sobre uma servidão voluntária. Exemplos nítidos disso são as minorias (mulheres, negros, pessoas LGBT) que gritam apoio a candidatos com discursos machistas, racistas, lgbtfóbicos, como Donald Trump nos Estados Unidos e Jair Bolsonaro no Brasil; ou o contraditório exemplo das manifestações que ocorreram no afã do impeachment da ex-presidenta Dilma Roussef, pedindo intervenção militar.

Faz-se mister discutir à luz de Deleuze e Guattari (2010) a ação das máquinas capitalísticas na criação de subjetividades microfascistas, onde os processos de desterritorialização, ${ }^{9}$ engendrados através de relações de forças do encontro entre diferenças, seguidos de uma retetorrialização, que faz da relação com a alteridade minoritária (seguindo o

\footnotetext{
${ }^{8}$ Acerca disso confira Para além da fronteira: O transbordo como conceito crítico, de Darlan Roberto dos Santos, disponível na Internet: http://www.ufjf.br/revistaipotesi/files/2016/01/10-Para-Alem-da-Fronteira.pdf.

${ }^{9}$ Com base na apropriação filosófica que fazem da Geografia, os autores pensam o conceito de" território" não no sentido de uma relação com a terra, mas, especificamente acerca da subjetivação. Nesse contexto, Guattari (2001) cria o conceito de Territórios Existenciais ou Subjetivos. Existem três movimentos ininterruptos e indissociáveis que revelam a perspectiva processual das subjetividades (singulares, coletivas, institucionais), a saber: a territorialização, onde o território mantém uma relação de considerável estabilidade em graus de quase nulas diferenciações; a desterritorialização, que é a destruição, desfiguração, diferenciação de um território; e a reterritorialização, que é a volta a uma "nova" organização que pode manter características da territorialização inicial, mas nunca é a repetição desta.
} 
sentido deleuzoguattariano de minoria não em termos quantitativos, mas do que foge ao padrão, ao hegemônico) uma relação de aniquilação, de anulação; ou, nas reterritorializações mais brandas, em uma relação de tolerância (palavra que tem ganhado força, sobretudo nas redes sociais), mas carrega subjacentemente um poder do eu em permitir que o outro experimente seus outramentos.

Para Rolnik (2018, p.34), enquanto a economia capitalista tradicional sobrevive por meio da exploração da força de trabalho para extração de mais-valia, as máquinas capitalísticas atuais funcionam por meio da expropriação da vida em seu potencial criativo, heterogenético e rizomático, o que a autora nomeia de "cafetinagem". A vida tomada de assalto, a vida cafetinada é afastada de sua potência de existir (e de resistir) por meio de uma colonização de inconscientes.

Não há sociedade capitalística que sobreviva sem a constituição de relações de dominação e opressão em que o status quo dos regimes majoritários como ordenadores e das minorias como subjugadas se perpetua. E como as máquinas capitalísticas também atuam nas subjetividades minoritárias, há uma interferência no sentido de reterritorializar as linhas de fuga das minorias em um desejo de fascismo.

Em suma, podemos observar que as subjetividades microfascistas não se encontram prontas, mas são produzidas no nível do desejo, dos movimentos dos territórios existenciais agenciados, sobretudo pela relação entre máquinas sociais e máquinas desejantes, o que constitui a modelização subjetiva principal das sociedades capitalísticas. Valendo ratificar que esses movimentos dos processos de subjetivação não são estáveis, nem tampouco identitários, mas experimentam movimentos de metamorfoses.

\section{Conclusão}

Este artigo é na verdade um convite para que possamos pensar a possibilidade de uma extrapolação conceitual e filosófica do termo "fascismo", para além apenas da sua referência política; ou então, para pensarmos em aspectos “menores” das relações políticas. Precisamente, aquelas que dizem respeito ao nosso dia-a-dia, a nossas práticas cotidianas, tomando para si não mais categorias absolutas, como "sujeito", "eu", "autoconsciência", mas pensando em certos "processos" que atravessam tais instâncias.

Ratificamos logo no início a ideia de que o fascismo de Estado não foi um movimento meramente pragmático, por assim dizer, como se não houvesse noções, pensamentos por detrás de cada proposta. Mussolini, chefe máximo do fascismo italiano à época, tinha sua compreensão 
acerca das supostas mazelas do marxismo, da proposta socialista, embora - e aí não há como discordar de autores como Leandro Konder - pouco acharíamos nas suas ideias de fundamentação filosoficamente adequada do movimento que encabeça. Muito mais atento a posições próprias, rígidas e, claro, dogmáticas, foram a personalidade e posturas fortes de Mussolini os determinantes das suas ações, não suas compreensões filosóficas acerca das correntes políticas sob sua lente, sobretudo marxismo e liberalismo capitalista.

Chegando na perspectiva micropolítica com Deleuze e Guattari, buscamos mostrar as diversas facetas de uma abordagem microfascista: o perigo do desejo fascista, a intromissão sutil e disfarçada de fascismos mesmo em supostos movimentos revolucionários, o papel do capitalismo na sua atenção aos sujeitos e, portanto, nos modos com os quais este sistema forma subjetividades. Muito embora Marx tenha pensado algo de semelhante, por exemplo mostrando como a superestrutura hegemônica burguesa forma seu arcabouço ideológico e o dissemina no todo social, certamente o pensamento de Deleuze e de Guattari, aqui delineado, acrescenta novidades a esse processo que cria sujeitos e subjetividades, que nos criam e nos recriam, afinal.

\section{REFERÊNCIAS BIBLIOGRÁFICAS}

DELEUZE, G., GUATTARI, G. Mil Platôs: capitalismo e esquizofrenia. v. 3. Rio de Janeiro: Ed. 34. 1996. Ed. 34. 2010.

O Anti-Édipo: capitalismo e esquizofrenia. Tradução de Luiz B. L. Orlandi. São Paulo:

DELEUZE, G., PARNET, C. Diálogos. São Paulo: Editora Escuta, 1998.

DELEUZE, G. Foucault. São Paulo: Brasiliense. 2005.

"Trechos selecionados da aula Anti-Édipo". Amaral, L (trad.). Fractal: Revista de Psicologia, 28(1), 160-169, 2006.

DOMÈNECH, M; TIRADO, F.; GÓMEZ. “A dobra: psicologia e subjetivação”. In: SILVA, T. (org.). Nunca fomos humanos: nos rastros do sujeito. Belo Horizonte: Autêntica, 2001.

ESQUIZOGRAFIAS. Desejo por Bolsonaro's. 2017. Disponível em: esquizografias.jimdo.com. Acesso em 28 julho de 2018.

FOUCAULT, M. "Foucault étudie la raison d'État". Dits et écrits. Paris: Gallimard, 1994.

. “O Anti-Édipo: uma Introdução à Vida Não Fascista”. In: DELEUZE \& GUATTARI. O anti-Édipo. Capitalismo e esquizofrenia, 1993.

. Microfísica do poder. Organização e tradução de Roberto Machado. Rio de Janeiro: Edições Graal, 2004.

GALLO, S. “Entre Édipos e o Anti-Édipo". In: RAGO, M. \& VEIGA-NETO. Para uma vida não fascista. Belo Horizonte: Autêntica, 2015. 
GUATTARI, F. Caosmose: um novo paradigma estético. Rio de Janeiro, Ed. 34., 2010. Cactus, 2013. Líneas de fuga: por otro mundo de posibles. Ciudad Autónoma de Buenos Aires:

GUATTARI, F., \& ROLNIK, S. Micropolítica: cartografias do desejo (4 ed.). Petrópolis: Vozes. 1993.

HUR, D. Psicologia, Política e Esquizoanálise. Campinas: Alínea, 2018.

KONDER, Leandro. Introdução ao Fascismo. Rio de Janeiro: Graal, 1977.

LACAN, J. O seminário: livro 5: as formações do inconsciente. Trad. Vera Ribeiro. Rio de Janeiro: Jorge Zahar, 1999.

MBEMBE, A. Necropolitica. São Paulo: N-1 Edições, 2018.

MANN, M. Fascistas. Rio de Janeiro: Record, 2008.

MUSSOLINI, Benito. A doutrina do Fascismo. Itália: Vallecchi Editore Firenze, 1935.

PARIS, Robert. As origens do Fascismo. Tradução de Elisabete Perez. São Paulo: Perspectiva, 1976.

PAXTON, R. Anatomia do Fascismo. São Paulo: Paz e Terra, 2007.

REICH, W. Psicologia de Massas do Fascismo. 3 ed. São Paulo: Martins Fontes, 1988.

ROLNIK, S. Esferas da Insurreição: Notas para uma Vida não Cafetinada. São Paulo: N-1 Edições, 2018.

SANTOS, Darlan Roberto dos. "Para além da fronteira: O transbordo como conceito crítico", de Darlan Roberto dos Santos, acessado na Internet dia 13 de abril de 2019: http://www.ufjf.br/revistaipotesi/files/2016/01/10-Para-Alem-da-Fronteira.pdf. 